J. Perinat. Med. 15 (1987) 53

\title{
Perinatal management of fetal hydronephrosis with normal bladder
}

\author{
Umberto Nicolini ${ }^{1}$, Enrico Ferrazzi ${ }^{1}$, Alessandra Kustermann ${ }^{1}$, Marina Ravizza ${ }^{1}$, \\ Maria Bellotti ${ }^{1}$, Giorgio Pardi ${ }^{1}$, Carlo Alberto dell'Agnola ${ }^{2}$, Vincenzo Toma- \\ selli $^{2}$, and Luciana Carmassi ${ }^{2}$
}

11st Department of Obstetrics and Gynecology, University of Milan, and

${ }^{2}$ Department of Pediatric Surgery, I.C.P. Milan, Italy

\section{Introduction}

Obstruction, vescico-ureteral reflux and parenchymal dysplasia are the most frequent congenital lesions of the uropoietic system. These anomalies are responsible for 30 to $40 \%$ of all cases of chronic renal insufficiency. In Europe the prevalence of these chronic diseases is estimated to be 20 in 1000000 children between 0 to 15 years [18].

The time of surgical correction is widely accepted as an important variable in reducing incidence of new cases which is about three to four per million per year. The best results are achieved in children operated on within the first year of life, following early diagnosis. After this stage, despite surgery, most of these patients progressively deteriorate to chronic renal insufficiency.

Renal lesions should be diagnosed before they progress to a state of "no return" which is frequently associated with and worsened by severe infections. These lesions are frequently symptomless until severe impairment has occurred. Early diagnosis cannot rely on clinical signs such as palpable abdominal mass, urinary infection, hematuria or micturition disorders, all of which are inconstant and may occur at a late stage in the disease. The combined use of diagnostic techniques such as sonography and urography may be based on selected popula- tion. Unfortunately, risk factors are hard to identify. Extensive sonographic screening in the neonatal period would be hard to perform and, in any case, should be considered only after a cost-benefit evaluation.

Recent experiences in some pediatric surgery centers have evidenced how, in the last few years, most cases of uropoietic lesions treated at an early stage are the result of diagnoses made during prenatal life [7]. At the beginning of the 1970's it became clear that prenatal sonography could achieve an accurate diagnosis of uropoietic anomalies. The subject of the present research is proper perinatal management of the various lesions observed. One of the main issues is whether or not it is advisable to carry out decompression on fetuses as well as on newborn infants.

In cases of oligohydramnios it is widely accepted that this procedure might benefit some fetuses because a severe reduction of amniotic fluid is a sign of closed obstruction to urine and/or advanced renal damage and represents, per se, an unfavorable prognostic factor, expecially as regards pulmonary hypoplasia $[10,11]$.

In those fetuses with an ultrasonic picture of hydronephrosis probably due to prevescical obstructions, the choice of management is complicated by the fact that, when the lesion is 
unilateral, the amount of amniotic fluid cannot be assumed as a reliable index. Surprisingly, polyhydramnios rather than oligohydramnios has been described in some bilateral cases [17].

Although some papers dealing with fetal hydronephrosis have included cases of upper urinary tract obstruction or vescico-ureteral reflux, until now no papers have been focused just on these cases alone; it is then difficult to draw definite criteria for proper management. For this purpose we report our experience in diagnosis and perinatal management of hydronephrosis not associated with overdistended bladder.

\section{Materials and methods}

This series covers 30 cases of prenatal diagnosis of uni- or bilateral hydronephrosis not associated with an overdistended bladder. Fifteen cases were referred for suspicious ultrasound findings while the others were from the obstetrical population of the hospital. Both real-time and static scanners were used in the study period (October 1979-June 1983).

Hydronephrosis was confirmed by three independent observers with more then one year's experience with obstetrical sonography. The operators did not agree on a diagnosis between hydronephrosis and dysplasia in only one case. Once the diagnosis was established, all patients underwent serial sonographic checks as well as routine fetal monitoring.

The severity of the urinary tract dilatation was assessed by a grade three scale (mild, moderate, severe: figures $1-3$ ) based on the ratio between kidney parenchyma and transonic mass. The evaluation of the disease was thereafter defined as unmodified, worsening or improving, if a change in the severity scale did or did not occur. The amniotic fluid was qualitatively evaluated as oligohydramnios, normal or polyhydramnios.

In no case was fetal urine aspirated or drained prenatally. Early delivery for post-natal decompression was performed at the 36 th week on four cases among seven fetuses with worsening

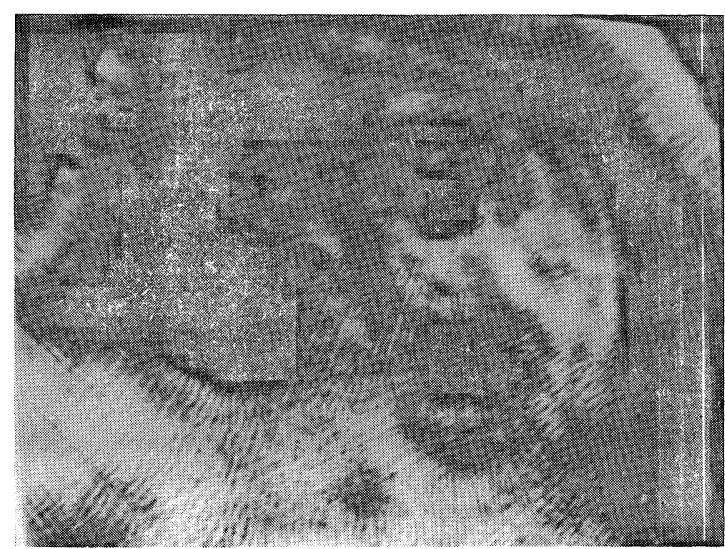

Figure 1. Mild bilateral hydronephrosis.

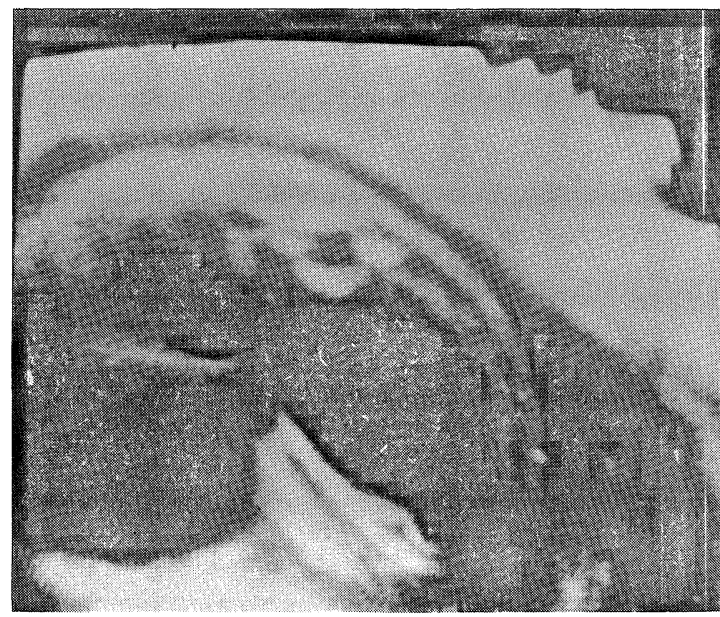

Figure 2. Bilateral hydronephrosis: left moderate, right severe.

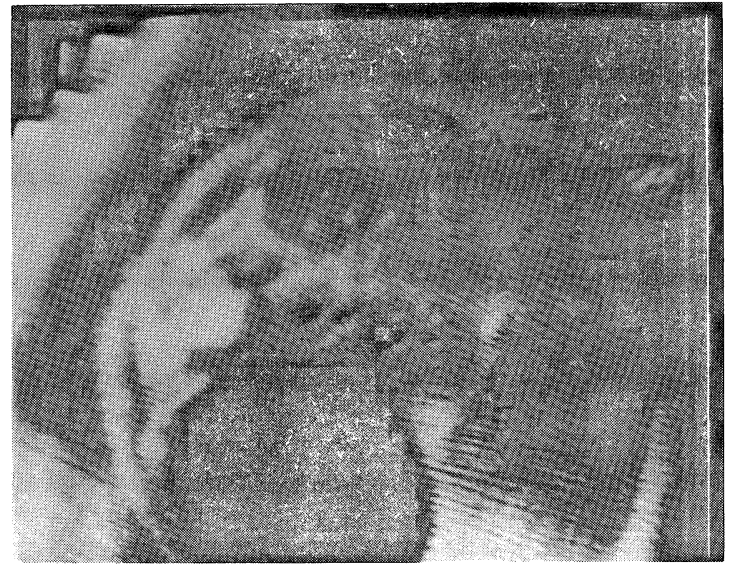

Figure 3. Unilateral hydronephrosis: severe. 
hydronephrosis (two unilateral and two bilateral) and in one case with severe oligohydramnios.

A cesarean section was performed in $25 \%$ of cases, but in no instances for reasons specifically referring to the fetal disease. According to Italian standards [9], neonatal weight was between the 10th and the 90th centile in 22 cases, below the 10th in 6 cases and above 90th in the remaining two.

The babies were clinically examined after birth especially to determinate whether palpable abdominal masses were present. Sonographic evidence of hydronephrosis in the newborn infants was quantified on a grade three scale $[6,7]$. In suspected or obviously abnormal cases, ultrasound examination was repeated within 1 to 7 days. When the sonographic picture of the uropoietic system was normal, the check was delayed for at least one month.

Urography with micturitional cystography was performed on all newborn infants with sonographic hydronephrosis ranging from moderate to severe as confirmed by at least two scans. Surgical correction was performed only in cases with urographic evidence of severe hydronephrosis or of functional "silence" of the kidney. In cases with bilateral pyelo-ureteric junction stenosis, surgery was performed on the less severely affected kidney first.

All newborn infants who underwent surgical management were followed up for several months. Five infants have been followed up for more than one year.

\section{Results}

In table I, results are summarized for what concerns correspondence between prenatal diagnosis and neonatal findings. Hydronephrosis was confirmed post-natally by ultrasound and by urography in 16 cases $(53.3 \%)$.

The doubtful case in which the diagnosis was uncertain between hydronephrosis and dysplasia is also included. All the cases of severe hydronephrosis as classified in utero belong to this group which also happens to include 5 cases of mild hydronephrosis.

In 15 of these cases, prenatal diagnosis of mono-bilaterality corresponded to the findings after birth. The only exception was normal when first checked in the first week of extrauterine life, but bilateral hydronephrosis was evidenced at ultrasound after three weeks. In this case final diagnosis was bilateral vescico-ureteric reflux (VUR); during prenatal life it appeared normal at the first ultrasound examination during the 34th week but displayed monolateral hydronephrosis at the 37th week. The most frequent cause of hydronephrosis proved to be pyelo-ureteric junction obstruction (PUJO) (12 of 16). One case diagnosed by prenatal ultrasound as unilateral hydronephrosis at surgery proved to have a multicystic kidney. In two cases $(6.7 \%)$ hydronephrosis cleared up during intrauterine life, one at the 37 th week following an ultrasonic evidence of unilateral hydronephrosis at the 33rd week, the other only one week after diagnosis of severe bilateral hydronephrosis at the 31st week. Both were

Table I. Correspondence between prenatal and neonatal diagnosis.

\begin{tabular}{lllll}
\hline $\begin{array}{l}\text { Prenatal } \\
\text { hydronephrosis }\end{array}$ & \multicolumn{2}{l}{ Neonatal diagnosis } & Dysplasia & \multirow{2}{*}{ Normal } \\
\cline { 2 - 4 } & Hydronephrosis & & \\
\cline { 2 - 5 } & Unilateral & Bilateral & 1 & $7^{*}$ \\
\hline Unilateral & 8 & 1 & - & $6^{*}$ \\
\hline Bilateral & - & 7 & 1 & 13 \\
\hline
\end{tabular}

* in two patients (one unilateral and one bilateral) hydronephrosis disappeared during prenatal age. 
considered normal after being followed up for 9 and 3 months respectively. Eleven other cases $(36.7 \%)$ were clinically and ecographically normal on neonatal follow-up. Only three $(19 \%)$ of the 16 cases confirmed at birth were diagnosed prior to 30 weeks. The percentage of ultrasound examinations prior to 30 weeks (of the total number of those performed between 25 and 35 weeks) in our laboratory is $41 \%$. The frequency of pathological cases after the 30th week is much higher than expected. This may suggest that obstructive hydronephrosis tends to occur late in gestation. However, only 8 cases out of 30 were examined and found normal before the diagnosis.

Oligohydramnios was observed only in 4 cases. One of these occurred among those affected by bilateral hydronephrosis. This was a fetus with trisomy 21, severe growth retardation and an atrial septum defect. The other three were normal at birth, while polyhydramnios was observed in three affected and one normal fetuses.

No intrauterine deaths occurred in this series. Table II reports the neonatal findings and surgical or pathological results. A palpable abdominal mass was found in 6 of 28 newborns. One of the later underwent nephrectomy for a multicystic kidney. Clinical findings were negative in ten patients with hydronephrosis (in one newborn infant with unilateral hydronephrosis this data was not reported on clinical records). First postnatal sonography control showed a moderate or severe hydronephrosis in 10 cases (the multicystic kidney is included as a wrong neonatal diagnosis). Such a sonographic picture occurred only after up to seven days in the remaining seven newborn infants later confirmed as being hydronephrotic. Routine laboratory examinations were normal in all cases. Only the first case in this series suffered from an urinary tract infection. This newborn was managed expectantly notwithstanding an abnormal echographic finding at the second week of life. A bilateral ureteral reimplantation had to be performed at the fourth month following the infection. Urography confirmed hydronephrosis in all patients with sonographic diagnosis of moderate or severe dilation confirmed in two ultrasound examinations. Death occurred in the trisomic newborn infant and in one case after surgery due to systemic sepsis.

Surgical procedures include:

- pyeloureteric junction plasty in 11 patients (15 kidneys),

- bilateral Cohen's reimplant in 2 patients,

- vescicoureteral plasty in 1 patient,

- nephrectomy in 1 patient,

- hymenectomy and drainage of hydrometrocolpos in 1 patient.

Table II. Neonatal findings in cases of prenatal diagnosis of hydronephrosis.

\begin{tabular}{|c|c|c|c|c|c|}
\hline \multirow{2}{*}{$\begin{array}{l}\text { Neonatal } \\
\text { diagnosis }\end{array}$} & \multirow{2}{*}{$\begin{array}{l}\text { Total } \\
\text { number } \\
\text { of cases }\end{array}$} & \multicolumn{4}{|c|}{ Neonatal findings } \\
\hline & & $\begin{array}{l}\text { Abdominal } \\
\text { palpable } \\
\text { mass }\end{array}$ & $\begin{array}{l}\text { Moderate or severe } \\
\text { hydronephrosis at } \\
\text { first ultrasound }\end{array}$ & $\begin{array}{l}\text { Hydronephrosis } \\
\text { at urography }\end{array}$ & $\begin{array}{l}\text { Surgical or } \\
\text { pathological } \\
\text { diagnosis }\end{array}$ \\
\hline $\begin{array}{l}\text { Unilateral } \\
\text { hydronephrosis }\end{array}$ & 8 & 2 & 4 & 8 & $\begin{array}{l}7 \text { PUJO } \\
1 \text { VUO }\end{array}$ \\
\hline $\begin{array}{l}\text { Bilateral } \\
\text { hydronephrosis }\end{array}$ & 8 & 3 & 5 & 8 & $\begin{array}{l}4 \text { PUJO } \\
2 \text { VUR } \\
1 \text { PUJO + VUJO } \\
1 \text { Hydrometro colpos }\end{array}$ \\
\hline Dysplasia & 1 & 1 & 1 & - & 1 Multicystic kidney \\
\hline Normal & 13 & - & - & - & - \\
\hline
\end{tabular}

PUJO = pyeloureteric junction obstruction; VUO = vescicoureteric obstruction; VUR = vescicoureteric reflux 
The time interval between prenatal diagnosis and surgical corrections ranged between 3 and 29 weeks. When fetal hydronephrosis showed a worsening pattern ( 7 patients, 12 kidneys) the mean interval was 10.3 weeks; in the others $(8$ patients, 10 kidneys, excluding the multicystic kidney) this was 13.8 weeks.

The kidneys of the four infants in whom pyeloureteric junction plasty was performed bilaterally showed at ultrasonic follow-up identical results for both sides, notwithstanding a mean interval of 4.5 weeks (range $1-9$ weeks) between the first surgical procedure and the second one on the controlateral kidney: in three cases sonographic picture was normal while in the fourth moderate bilateral hydronephrosis was found.

Two other patients still have moderate hydronephrosis at sonographic postsurgical follow-up. All three underwent pyeloureteric junction plasty in the first week of life; the time interval between prenatal diagnosis and surgery was 7 and 8 weeks.

\section{Discussion}

In our previous report in which we analyzed the effectiveness of routine ultrasound screening for fetal malformations, the frequency of uropoietic system anomalies was $26 \%$ of all congenital defects observed [16]. The frequency remained unchanged during the period covered by the present study $(55 / 220,25 \%)$. Hydronephrosis was by far the most frequent lesion (32 cases), which showed an association with an overdistended bladder in only two cases.

Hydronephrosis is then among the most frequent fetal anomalies that the ostetrician has to face with all that implies in terms of counseling to the parents, planning time and place of delivery and considering the possibility of prenatal treatment.

Until now eleven papers $[1,5,8,10,11,12,14$, $15,19,20,21]$ reported a total of 36 cases of fetal hydronephrosis presumably not due to low urinary tract obstruction with controlled neonatal outcomes. Therapeutic abortions were performed in two cases, postnatal surgery in twenty, severe associated malformations occurred in five cases and neonatal mortality was $14 \%$ mostly due to malformations other than hydronephrosis.

On the other hand, the frequency of false positive cases was $27.8 \%$. The rate of disappearance of fetal hydronephrosis during pre- or postnatal life was higher in the present series $(43.4 \%)$; this could be due to a less rigid definition of hydronephrosis; but it is difficult to be ascertained because neither the other authors give clear criteria to discriminate between physiologic and pathologic dilatation of the calycopyelic system. As a matter of fact, the degree of dilatation did not correlate, in our experience, with the chances of disappearance and also mild hydronephrosis had to be followed up carefully; moreover possibilities of misdiagnosis, which occurred in one case of multicystic kidney, had to be considered. In our experience, isolated hydronephrosis, whether uni- or bilateral, did not result in the fetuses being at high risk as regards their chance of survival, as only one case of death occurred due to sepsis after surgery, nor as regards to perinatal morbidity other that following the uropoietic lesion: only four infants were delivered before the 37 th week, birth weight was appropriate for gestational age in $73 \%$ of the cases, and in only one fetus were associated malformations observed. The sonographic appearance of this lesion seems to occur late in the course of gestation: the observed frequency of diagnosis after 30 weeks is in fact higher than would be expected if its onset was randomly distributed throughtout pregnancy.

This latter finding is in agreement with other authors' experiences which report diagnosis of the disease at a later stage of gestation than the one observed when other uropathies are diagnosed [11, 19]. The hypothesis of a late occurrence in gestation seems quite consistent and possibly related to the marked increase in the fetal urinary production. 
The hourly fetal urinary production rate doubles in fact from the 27 th to the 32 nd week [4] while in the same time interval the length and antero-posterior diameter of the kidney increase by only $15-25 \%$ [3]. Another explanation might be the earlier selection of cases of low urinary tract obstruction and hence earlier ultrasonic examination for a more frequent clinical evidence of oligohydramnios; whereas scanty amniotic fluid is a rare feature in cases of upper urinary tract obstruction, even in bilateral ones.

In this series, seven of the eight cases of bilateral hydronephrosis did not show a reduction of amniotic fluid, suggesting a favorable prognosis. In unilateral cases no estimation could be drawn, on the other side, for what concerns renal damage or the degree of obstruction to urine. Moreover, these patients are more likely to be undiagnosed at birth while the utility of early surgical management has been demonstrated exactly in such cases. In this series $66 \%$ of the newborn infants showed no clinical signs or symptoms and the first ultrasound examination after birth revealed only mild hydronephrosis in seven patients, in whom the progress of the disease was later confirmed by means of urography. On the other hand, in five cases only a minor degree of hydronephrosis was seen in utero, which developed postnatally into a severe form of the disease. Therefore in our own experience, the need for surgical correction is not strictly related to the degree of hydronephrosis evidenced in the antenatal or immediate neonatal period. In 1982 BERKOWITZ [2] stated that "unilateral lesions ... do not warrant the risks of shunt placement". We feel this opinion reasonable in view of this poor correspondence between degree of fetal hydronephrosis and need for neonatal surgery and possible disappearance of dilatation before birth.

However, we initially assumed that early delivery might allow earlier neonatal treatment. We were conscious of the greater perinatal risk related to prematurity and low birth weight, and we were looking for indicators to assist us in selecting cases in which this management was advisable. The quantity of amniotic fluid was not an useful indication because most of the cases were unilateral upper obstructions, therefore premature delivery was carried out in a few cases where the ultrasonic picture of fetal hydronephrosis was worsening or severe enough to lead to difficulties in differential diagnosis. This policy has been abandoned over the last two years when it became evident that mortality, morbidity and renal damage are not related to the time elapsing between prenatal diagnosis of hydronephrosis and surgery, when performed in the neonatal period. This is demonstrated by the cases of bilateral hydronephrosis in which, notwithstanding correction up to nine weeks earlier on the least affected kidney, both kidneys showed identical morphological results. Conservative management was adopted thereby decreasing surgical risks due to prematurity and low birth weight. Pyelo-amniotic shunts and early delivery may be necessary in some very severe obstructions of the upper urinary tract. We have never observed any such cases, which seem so far to be extremely rare.

Finally, preliminary data on renal functional evaluation of the patients who underwent surgical operation seem reassuring [13], but a longer follow-up is needed to draw definite conclusions.

\section{Summary}

This report covers 30 cases of prenatal diagnosis of uni- or bilateral hydronephrosis not associated with an overdistended bladder. Oligohydramnios was observed only in four cases while polyhydramnios occurred in three affected fetuses. In no case was fetal urine aspirated or drained prenatally. Early delivery was performed in four cases with oligohydramnios. Sixteen newborns required surgical correction of the lesion as it was confirmed by urography, following at least two sonographic examinations which confirmed a moderate to severe hydronephrosis after birth. The most frequent lesion was pyelo-ureteric junction obstruction (12 cases). Thirteen 
cases were normal at follow-up, and in two of these the dilation cleared up during intrauterine life. One case of severe hydronephrosis proved to be a multicystic kidney. In this series isolated hydronephrosis, both uni- or bilateral did not result in fetuses being at high risk for survival (only one infant died after surgery) nor as regards to associated malformations and perinatal morbidity. Provided a properly timed surgical correction was performed, renal function resulted to be good at follow-up.

Keywords: Fetal malformations, prenatal diagnosis, ultrasound.

\section{Zusammenfassung}

\section{Perinatales Management bei fetaler Hydronephrose und} unauffälliger Harnblase

Die Untersuchungsreihe umfaßt 30 Fälle, in denen pränatal eine uni- oder bilaterale Hydronephrose diagnostiziert wurde. In 4 Fällen bestand ein Oligo-, in 3 Fällen ein Polyhydramnion. Eine pränatale Aspiration oder Drainage von fetalem Urin erfolgte in keinem Fall. Bei den 4 Fällen mit Oligohydramnion wurde die Geburt frühzeitig eingeleitet. Bei 16 Neugeborenen war, nachdem der Verdacht durch eine Urographie bestätigt worden war, ein chirurgischer Eingriff zur Korrektur der Fehlbildung notwendig. Mindestens 2 ultrasonographische Untersuchungen wurden postnatal zur Bestätigung der mittelgradigen bzw. ausgeprägten Hydronephrose durchgeführt. Die häufigste Fehlbildung bestand in einer Obstruktion im Bereich der Ureterenabgänge (12 Fälle). Bei der Nachuntersuchung waren 12 Kinder unauffällig; darunter waren 2, bei denen sich die Dilatation schon intrauterin verringert hatte.

In unserer Untersuchungsreihe war eine isolierte Hydronephrose (uni- oder bilateral) weder mit einer stark erhöhten perinatalen Mortalität noch Morbidität verknüpft; (lediglich 1 Kind starb nach dem chirurgischen Eingriff). Assoziierte Mißbildungen kamen nicht gehäuft vor. Wie die Nachuntersuchung zeigt, ist die renale Funktion nach einer rechtzeitig durchgeführten chirurgischen Korrektur gut.

Schlüsselwörter: Fetale Mißbildungen, pränatale Diagnose, Ultraschall.

\section{Résumé}

Prise en charge périnatale de l'hydronéphrose fortale à vessie normale

Cette série représente 30 cas de diagnostic prénatal d'hydronéphrose uni ou bilatérale sans distention vésicale. On n'a observé un oligoamnios que dans quatre cas, alors qu'il y avait trois hydramnios. Il n'y a pas eu de cas où l'urine fotale a été aspirée ou drainée avant la naissance. Dans les quatre cas avec oligoamnios, un accouchement précoce a été provoqué. Seize nouveauxnés ont necessité d'un traitement chirurgical de la lésion confirmée par urographie; ce traitement a été réalisé après au moins deux examens échographiques ayant confirmé après la naissance une hydronéphrose modérée ou sévère. La lésion la plus fréquente est l'obstruction de la jonction pyélo-calicielle (12 cas). Treize cas ont été normaux lors du suivi, dont deux chez lesquelles la dilatation s'était améliorée au cours de la vie intrautérine. Un cas d'hydronéphrose sévère correspondait à un rein polykystique.

Dans cette série, l'hydronéphrose isolée, qu'elle soit unie ou bilatérale n'entraîne pas pour le fœtus un haut risque pour sa survie (un enfant seulement est décédé après chirurgie) ni en ce qui concerne les malformations associées et la morbidité périnatale. La fonction rénale secondaire à une correction chirurgicale réalisée au moment approprié est excellente lors du suivi ultérieur.

Mots-clés: Diagnostic prénatal, malformations fœtales, ultrasons.

Acknowledgements: This work was supported by research grant No. 84.02228.56.115.02636 from the Italian National Research Council (C.N.R.).

\section{References}

[1] Badlani G, HJ Abrams, S Kumari: Diagnosis of fetal hydronephrosis in utero using ultrasound. Urology 16 (1980) 315

[2] Berkowitz RL, MG Glickman, GJ WalKer Smith, NJ Siegel, RM Weiss, MJ Mahoney, JC HoBBins: Fetal urinary tract obstruction: what is the role of surgical intervention in utero? Am J Obstet Gynecol 144 (1982) 367
[3] Bertagnoli L, F Lalatta, R Gallicchio, M FanTUZZI, M RuSCA, A ZoRzoli, RL Deter: Quantitative characterization of the growth of the fetal kidney. J Clin Ultrasound 11 (1983) 349

[4] Campbell S, JW Wladimiroff, CJ Dewhurst: The antenatal measurement of fetal urine production. $\mathrm{J}$ Obstet Gynaecol Br Cwlth 80 (1973) 680 
[5] Cass A, S Smith, C Godec, K Veeraragavan, S TSAI, R BENDEL: Prenatal diagnosis of fetal urinary tract abnormalities by ultrasound. Urology 18 (1981) 197

[6] dell'Agnola CA, L Carmassi, V Tomaselli, M TOIA, U Politi, A SARTORI: The usefulness of ultrasound in the post operative management of hydronephrosis. Int J Ped Nephrol 5 (1984) 215

[7] Dell'Agnola CA, V Tomaselli, E Ferrazzi, A Kustermann, U Nicolini: Perinatal ultrasound monitoring: early detection and treatment of congenital uropathy. Br J Urol 55 (1983) 469

[8] Gruenewald SM, EF Crocker, AG Walker, BJ TRUDINGER: Antenatal diagnosis of urinary tract abnormalities: correlation of ultrasound appearance with postnatal diagnosis. Am J Obstet Gynecol 148 (1984) 278

[9] GrupPo di LAVORO DELla RICERCA Policentrica LONGITUdinAle OsteTrico-Pediatrica: Standard del peso del neonato italiano. Riv Ital Pediatr 6 (1980) 153

[10] HaRrison MR, MS Golbus, RA Filly, DK Nakayama, PW Callen, AA de Lorimier, H HriCAK: Management of the fetus with congenital hydronephrosis. J Pediatr Surg 17 (1982) 728

[11] Hobbins JC, R Romero, P Grannum, RL BerkoWitz, M Cullen, M Mahoney: Antenatal diagnosis of renal anomalies with ultrasound. Am J Obstet Gynecol 148 (1984) 868

[12] LEE TG, S BLAKE: Prenatal fetal abdominal ultrasonography and diagnosis. Radiology 124 (1977) 475

[13] Marra G, A Claris Appiani, K Goj, L Rossi, G Cavanna, BM Assael, SA Tirelli: L'evoluzione della funzione renale in bambini operati in epoca neonatale. Prospet Pediatr 15 (1985) 185
[14] Martin JJ, ES TAYlor: Diagnosis of bilateral hydronephrosis in utero by ultrasonography. Urology 17 (1981) 272

[15] MC FAYDEN IR, JS WIGGLESWORTH: Fetal urinary tract obstruction: is active intervention before delivery indicated? Br J Obstet Gynaecol 90 (1983) 342

[16] Nicolini U, E Ferrazzi, A Kustermann, M RaVIZZA, G PARDI: Effectiveness of routine ultrasound in screening congenital defects. J Perinat Med 10 (1982) 125

[17] Philipson EH, RN Wolfson, KR Kedia: Fetal hydronephrosis and polyhydramnios associated with vescico-ureteral reflux. J Clin Ultrasound 12 (1984) 585

[18] Proceedings of the European Dialysis and Transplantation Association. Vol. 17. B. H. B. Robinson Pitman Medical, London 1980

[19] SANDERS R, D Graham: Twelve cases of hydronephrosis in utero diagnosed by ultrasonography. J Ultrasound Med 1 (1982) 341

[20] Walzer A, M Koenigsberg: Prenatal evaluation of partial obstruction of the urinary tract. Radiology 135 (1980) 93

[21] WeINER S: The spectrum of fetal bladder outlet obstruction. Paper 502 presented at the annual meeting A. I. U. M. San Francisco 1981

Received June 18, 1985. Revised January 16, 1986. Accepted February 1, 1986.

Dr. Umberto Nicolini Istituto Ostetrico Ginecologico "L. Mangiagalli" dell'Università di Milano Via Commenda 12 I-20122 Milano, Italy 